\title{
Effects of Coupling Agents on the Properties of Cotton Stalk-Polypropylene Film Boards
}

\author{
Nan Xia, ${ }^{a}$ Fei Li, ${ }^{a}$ Kunfeng Liu, ${ }^{\text {a,b }}$ Ying Shao, ${ }^{a}$ Shujie Xing, ${ }^{a}$ Kangquan Guo ${ }^{c}, *$ \\ Effects of treating cotton stalks with a coupling agent (maleic anhydride \\ polypropylene (MAPP), polymeric methylene diphenyl diisocyanate \\ (PMDI), or vinyltrimethoxysilane (A171)) were investigated relative to the \\ mechanical and water resistance properties of cotton stalk-polypropylene \\ film boards. The interfacial morphology was investigated by scanning \\ electron microscopy (SEM). The results showed that the properties of the \\ boards increased with the incorporation of MAPP or PMDI up to $2 \mathrm{wt} \%$, or \\ with $\mathrm{A} 171$ up to $3 \mathrm{wt} \%$, but further increases in the coupling agent contents \\ decreased the properties. Boards treated with $2 \mathrm{wt} \%$ PMDI exhibited \\ optimum properties, with a $39.0 \%$ increase in modulus of rupture, a $38.2 \%$ \\ increase in modulus of elasticity, a $68.4 \%$ increase in internal bond, and a \\ $57.4 \%$ decrease in thickness swelling, compared with untreated boards. \\ The SEM micrographs further confirmed an efficient fiber-film adhesion in \\ the coupling-agent-treated boards.
}

Keywords: Cotton stalks; Polypropylene films; Coupling agents; boards; Mechanical properties; Thickness swelling

Contact information: a: College of Food Science, Xinyang Agriculture and Forestry University, 1 Beihuan Road, Xinyang, Henan Province 464000, China; b: School of Food Science and Technology, Jiangnan University, 1800 Lihu Road, Wuxi, Jiangsu Province 214122, China; c: College of Mechanical and Electronic Engineering, Northwest A\&F University, 22 Xinong Road, Yangling, Shaanxi Province 712100, China; *Corresponding author: jdguokq@126.com

\section{INTRODUCTION}

Natural fiber reinforced polymer composites (NFPCs) have attracted considerable interest from researchers and industrialists in recent years because of the increasing price of petroleum, ecological concerns, and the impending depletion of fossil fuels (Zhang 2014). NFPC is a product that can be made from natural fibers (such as flax, bamboo, hemp, sisal, jute, and wood fibers) and plastics (such as high-density polyethylene (HDPE), polypropylene, polyvinyl chloride, and thermoset plastics). NFPCs have extensive applications in building and civil engineering because of their many advantages, such as their light weight, stiffness, good workability, and recyclability (Kalia et al. 2009; Qi et al. 2012; Jariwala and Jain 2019). The main problem with NFPCs is the incompatibility between the hydrophilic natural fibers and hydrophobic plastics, which results in weak adhesion at the two-phase interface and, consequently, poor mechanical and physical properties.

To improve the interfacial adhesion between hydrophilic natural fibers and hydrophobic plastics, several methods based on physical or chemical modification of natural fibers or plastics have been reported in the literature (Zhao et al. 2012; Ben Mbarek et al. 2013; Sobczak et al. 2013; Yan et al. 2013; Verma and Jain 2017; Wang et al. 2019; Tanasă et al. 2020). Askanian et al. (2015) investigated the mechanical and viscoelastic properties of wood-polypropylene composites prepared with thermally modified fibers. 
Their results showed that treatment by rectification at $280^{\circ} \mathrm{C}$ increased the hydrophobicity of the wood fibers, leading to better dispersion and greater tensile modulus. Aydemir et al. (2015) studied the influence of heat-treated and untreated wood fillers on the mechanical and rheological properties of wood-nylon 6 composites and found that heat-treated composites had greater tensile strength, greater storage modulus, steady shear viscosity, and lower loss factor. Ou et al. (2014) examined effects of poplar wood fiber modified with glutaraldehyde and 1,3-dimethylol-4,5-dihydroxyethyleneurea on the rheological properties of wood flour/HDPE composites. Their results indicated that chemical modification of wood flour is a promising approach to improve the processability of highly filled wood-thermoplastic composites via extrusion/injection molding processing.

Researchers have found that adding a coupling agent, such as maleic anhydride grafted polypropylene (MAPP), silane, titanate, aluminate, isocyanate, or phthalic anhydride, is one way to greatly improve the mechanical properties of NFPCs by improving interfacial compatibility (Xie et al. 2010a; Kumar et al. 2011; Abdul Khalil et al. 2013; Sobczak et al. 2013; Poletto and Zattera 2017; Jin et al. 2019; Pisanu et al. 2019). Among those, MAPP is one of the most widely used, as it is an effective coupling agent for improving interfacial adhesion. Homkhiew et al. (2015) investigated the effects of composition on the mechanical and physical properties of polypropylene/rubber wood flour composites and found that adding 4\% MAPP can yield good mechanical properties. Naghmouchi et al. (2015) studied the effects of fiber loading and MAPP on the physical properties of wood flour/polypropylene composites. The results showed that composites containing MAPP exhibited the best mechanical properties and decreased the negative effects of water absorption. It was indicated that MAPP, which contains both polar and nonpolar groups, might produce a molecular bridge between natural fibers and plastics by forming physical and/or chemical bonds and benefit the dispersion of plastics into natural fibers, which ultimately results in decreased interfacial tension between the natural fibers and the plastics.

Yu et al. (2013) and Xue et al. (2013) investigated the effects of polymeric methylene diphenyl diisocyanate (PMDI) content and silvergrass fiber content on the physical, mechanical, and thermal properties of silvergrass-reinforced HDPE composites. They found that composites with PMDI treatment had better mechanical properties, lower water absorption, and better thermal stability. Fang et al. (2014) used poplar veneer that had been treated with vinyltrimethoxysilane (A171) to fabricate wood-HDPE plywood and found that treated plywood had a greater storage modulus and lower $\tan \delta$ peak values.

The objective of this study was to investigate the suitability of MAPP, PMDI, and A171 as coupling agents for the fabrication of cotton stalk-polypropylene film boards (CPBs). A systematic investigation on the effects of coupling agent content was undertaken to obtain optimal mechanical properties and thickness swelling.

\section{EXPERIMENTAL}

\section{Materials}

Cotton stalks were obtained from farmlands in Shaanxi province, China. The cotton stalks were from upland cotton (Gossypium hirsutum). Table 1 shows the main chemical components of the cotton stalks. The lateral branches and roots of the cotton stalks were manually removed. The cotton stalks were cut to a length of $40 \mathrm{~cm}$ using a table saw, impregnated in boiling water for $3 \mathrm{~h}$, peeled in a self-made peeling machine, and then oven- 
dried at $103( \pm 2){ }^{\circ} \mathrm{C}$ to a moisture content of less than $3 \%$. The average length to diameter ratio of cotton stalk bundles was 80 , with a density of $0.332 \mathrm{~g} / \mathrm{cm}^{3}$. Isotactic polypropylene (PP) films were purchased from Dongguan Plastic Raw Material Company, Ltd. (Dongguan, China), with a density of $0.91 \mathrm{~g} / \mathrm{cm}^{3}$ and a melt flow index of $30 \mathrm{~g} / 10 \mathrm{~min}$ at $230{ }^{\circ} \mathrm{C}$. Maleic anhydride grafted polypropylene (MAPP) was supplied by Petro China Company, Ltd. (Beijing, China), with a maleic anhydride grafting ratio of $0.8 \%$ to $1.0 \%$ and a melt flow index of $50 \mathrm{~g} / 10 \mathrm{~min}$ to $80 \mathrm{~g} / 10 \mathrm{~min}$ at $190{ }^{\circ} \mathrm{C}$. Polymeric methylene diphenyl diisocyanate (PMDI) resin was obtained from Novofibre Panel Company (Yangling, China) with an -NCO content of $31.7 \%$ and a solid content of $100 \%$. Vinyltrimethoxysilane (A171) was purchased from Xi'an Guihai Company (Xi'an, China) with a solid content of $98 \%$.

Table 1. Main Chemical Components of Cotton Stalks (Qi et al. 2012)

\begin{tabular}{|c|c|c|c|c|c|}
\hline Chemical Components & $\begin{array}{c}\text { Cellulose } \\
(\%)\end{array}$ & $\begin{array}{c}\text { Hemicellulose } \\
(\%)\end{array}$ & $\begin{array}{c}\text { Lignin } \\
(\%)\end{array}$ & $\begin{array}{c}\text { Ash } \\
(\%)\end{array}$ & $\begin{array}{c}\text { Hot Water } \\
\text { Extractives } \\
(\%)\end{array}$ \\
\hline Bark & 41.20 & 17.04 & 19.28 & 5.68 & 12.12 \\
\hline Pith & 35.02 & 20.15 & 17.46 & 3.15 & 6.31 \\
\hline Whole cotton stalk & 43.18 & 19.01 & 21.05 & 3.09 & 7.64 \\
\hline
\end{tabular}

\section{Methods}

MAPP modification

MAPP flour was homogenously sprayed onto cotton stalks at contents of $0 \mathrm{wt} \%, 1$ $\mathrm{wt} \%, 2 \mathrm{wt} \%, 3 \mathrm{wt} \%$, and $4 \mathrm{wt} \%$, respectively (based on the CPBs' weight).

\section{PMDI modification}

PMDI resin was homogenously sprayed onto cotton stalks at contents of $0 \mathrm{wt} \%, 1$ $\mathrm{wt} \%, 2 \mathrm{wt} \%, 3 \mathrm{wt} \%$, and $4 \mathrm{wt} \%$, respectively (based on the CPBs' weight).

\section{A171 modification}

Cotton stalks were first soaked in A171 solution at room temperature for $2 \mathrm{~h}$, and then taken out with distilled water filtration. The concentration of A171 solution was 0 $\mathrm{wt} \%, 1 \mathrm{wt} \%, 2 \mathrm{wt} \%, 3 \mathrm{wt} \%$, and $4 \mathrm{wt} \%$, respectively (based on the CPBs' weight). The treated cotton stalks were oven-dried to a constant weight at $103( \pm 2){ }^{\circ} \mathrm{C}$. The modified cotton stalks were then cooled to room temperature and kept in bags for end-use.

\section{Sample preparation}

A series of CPBs containing 10 wt\% of PP films with MAPP-, PMDI-, or A171treated cotton stalks were prepared. Table 2 presents the factors and levels of the experiments with three replicates for each level. The processing method for the fabrication of CPBs is shown in Fig. 1. The cotton stalk bundles were first oven-dried and modified by coupling agents and were then divided into two equal portions. Each portion was formed into a single unidirectional layer and pre-pressed at room temperature. Then, the prepressed layers and PP films were stacked to form a mat on a stainless steel caul with a wooden mold frame. The PP films were placed between the pre-pressed layers and on the outside surfaces of the mat. The number of PP films introduced at each layer was adjusted 
according to the targeted PP content in that panel. Another caul was placed on top of the mat after forming, and two mold-releasing papers were used to prevent adhesion between the mat and the caul. The formed mat was then hot-pressed at a pressure of $5 \mathrm{MPa}$. The thickness of the panel was controlled to $10 \mathrm{~mm}$ by two thickness gauges. The whole process was program-controlled. Finally, the heater was turned off, and the panel was cooled to room temperature before it was removed. The pressed panel was then trimmed to a final size of $300 \mathrm{~mm} \times 300 \mathrm{~mm} \times 10 \mathrm{~mm}$, with a density of $0.7 \mathrm{~g} / \mathrm{cm}^{3}$.

Table 2. Experimental Design and Formulation

\begin{tabular}{|c|c|c|c|}
\hline Sample Code & $\begin{array}{c}\text { Coupling Agent Content } \\
(w t \%)\end{array}$ & $\begin{array}{c}\text { PP Content } \\
(w t \%)\end{array}$ & $\begin{array}{c}\text { Cotton Stalk Content } \\
\text { (wt\%) }\end{array}$ \\
\hline M0, P0, A0 & 0 & 10 & 90 \\
\hline M1 & 1 & 10 & 89 \\
\hline M2 & 2 & 10 & 88 \\
\hline M3 & 3 & 10 & 87 \\
\hline M4 & 4 & 10 & 86 \\
\hline P1 & 1 & 10 & 89 \\
\hline P2 & 2 & 10 & 88 \\
\hline P3 & 3 & 10 & 87 \\
\hline P4 & 4 & 10 & 86 \\
\hline A1 & 1 & 10 & 88 \\
\hline A2 & 2 & 10 & 87 \\
\hline A3 & 3 & 10 & 86 \\
\hline A4 & 4 & 10 & 89 \\
\hline \multicolumn{2}{|l|}{ Notes: M means modified by MAPP, P means modified by PMDI, A means modified by A171. } \\
\hline
\end{tabular}

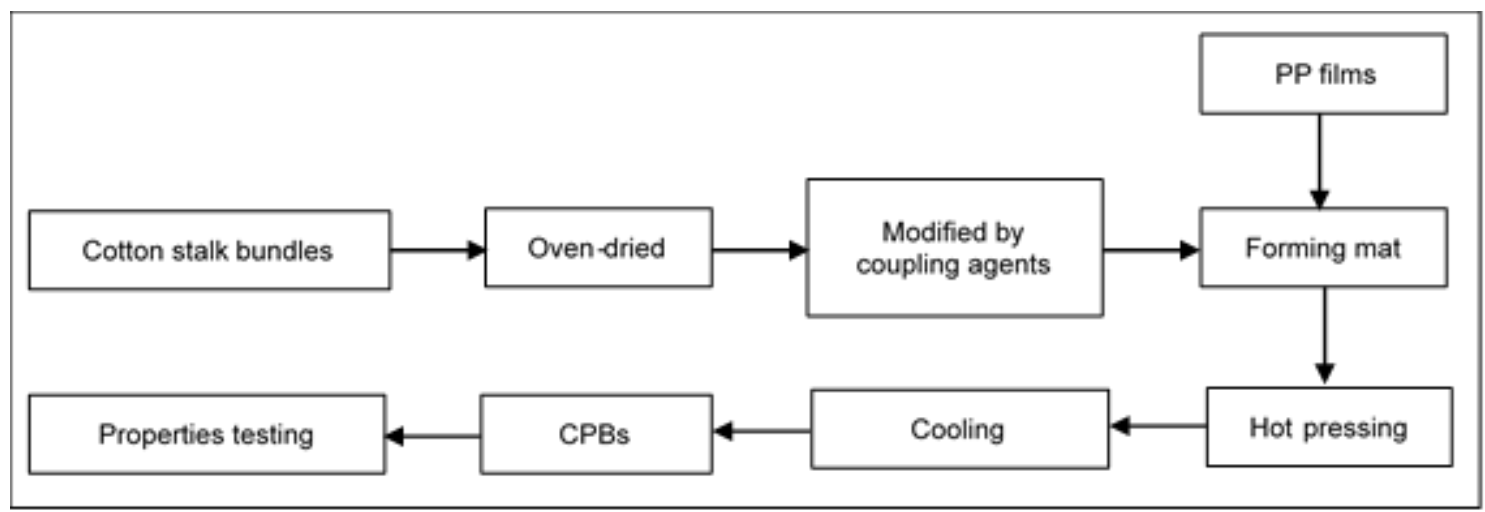

Fig. 1. Fabrication processes of cotton stalk-polypropylene film boards

\section{Composite characterization}

Prior to testing, samples were conditioned in a climate-controlled room at $20{ }^{\circ} \mathrm{C}$ and $65 \%$ relative humidity for a week. The specimen dimensions for the modulus of rupture (MOR), the modulus of elasticity (MOE), the internal bond (IB), and thickness swelling test were $250 \mathrm{~mm} \times 50 \mathrm{~mm}$ and $50 \mathrm{~mm} \times 50 \mathrm{~mm}$, respectively (Fig. 2). 


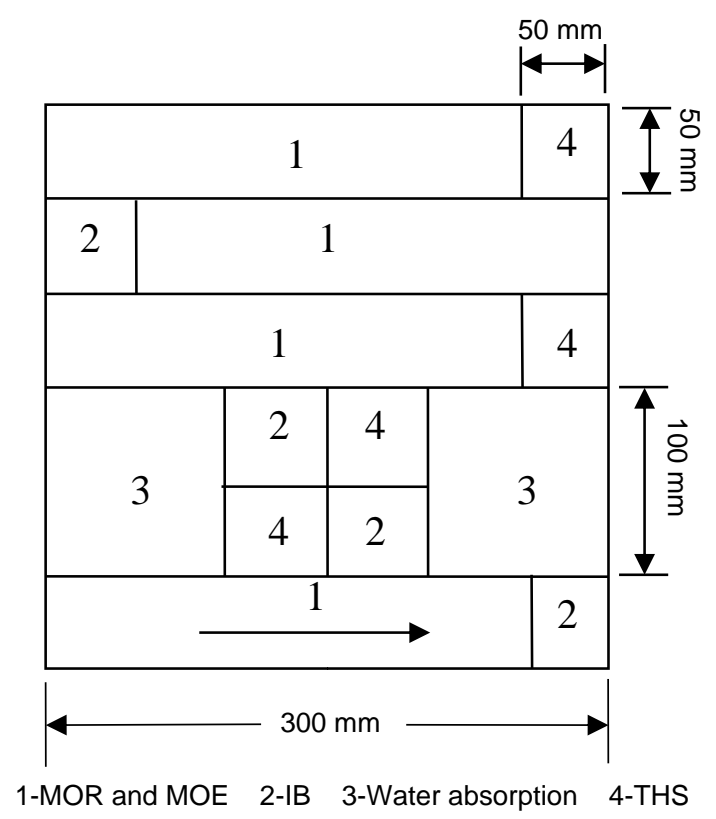

Fig. 2. Distribution of testing specimens (the arrow is parallel to the direction of the cotton stalk bundles)

The three-point static bending MOE and MOR, as well as IB and thickness swelling, were evaluated according to GB/T 17657 (2013), and mechanical properties were tested with a SANS testing machine (CMT5504, Shenzhen SANS Material Testing CO., LTD., Shenzhen, China). The speed of the static bending test was $5 \mathrm{~mm} / \mathrm{min}$, while IB testing was at $3 \mathrm{~mm} / \mathrm{min}$. The thickness swelling test was performed with a continuous submersion time of $24 \mathrm{~h}$ in distilled water. Properties were evaluated parallel to the length direction of the samples due to the limited panel size. The data were analyzed using SPSS (Version 20, IBM, Armonk, NY, USA).

The microstructures of the CPBs were examined with a scanning electron microscope (JSM-6360LV, JEOL, Tokyo, Japan). The fractured surfaces of the specimens were dried in a vacuum for $0.5 \mathrm{~h}$ and then gold-sputtered (JFC-1600, JEOL, Tokyo, Japan) before testing.

\section{Statistical Analysis}

Data for each test were statistically analyzed with SPSS 20.0 software (IBM, Armonk, NY, USA). All data were expressed as the mean value \pm the standard deviation. Figures were drawn with Origin Pro 9.1 software (Origin Lab, Northampton, MA, USA).

\section{RESULTS AND DISCUSSION}

\section{Effects of Coupling Agents on the Mechanical Properties of CPBs}

Figure 3 illustrates the mechanical properties of the CPBs reinforced with coupling agent-treated cotton stalks. The incorporation of coupling agents and cotton stalks increased the mechanical properties of the boards. There was a gradual increase in the MOR, MOE, and IB of the CPBs as the PMDI or MAPP content varied from $0 \mathrm{wt} \%$ to 2 
wt $\%$. Compared with the untreated CPBs, the MOR, MOE, and IB of $2 \mathrm{wt} \%$ PMDI-treated boards increased by $39.0 \%, 38.2 \%$, and $68.4 \%$, respectively. This improvement may be attributed to the increased wetting of the PP films within the cotton stalks, which leads to an efficient stress transfer from the PP films to the fibers. It has been hypothesized that isocyanate groups can build covalent bonds with the surface hydroxyl groups of fibers (Karmarkar et al. 2007; Huang et al. 2018). Therefore, the hydrophobic films and hydrophilic fibers became more compatible because the -NCO functional group of PMDI can build covalent bonds with the hydroxyl groups of fibers, which can decrease the hydrophilicity of the cotton stalk fibers (Xue et al. 2015). However, when adding even more PMDI to the boards, all the mechanical properties were decreased. It may be that the excess dosage of PMDI could lead to agglomeration and restrict the mobility of the PP chains, thereby producing a relatively weak interface and leading to easier composite failure.

There was a relative increase in the mechanical properties of the CPBs when increasing in MAPP content from $0 \mathrm{wt} \%$ to $2 \mathrm{wt} \%$. Compared with the untreated boards, there was a $22.9 \%$ increase in MOR, a $17.0 \%$ increase in MOE, and a $52.6 \%$ increase in IB for the $2 \mathrm{wt} \%$ MAPP-treated CPBs. This increase in mechanical properties may be due to coupling reactions between the hydroxyl groups of cotton stalk fibers and the anhydride groups of MAPP, thereby forming ester linkages. The PP part of MAPP became compatible with the PP films, which further contributed to an efficient stress transfer from the PP films to the fibers. When MAPP is added, surface crystallization dominates over bulk crystallization and a transcrystalline layer is formed around the cotton stalk fibers (Ashori and Nourbakhsh 2009; Ma et al. 2017; Daghigh et al. 2018). Crystallites have much greater moduli compared with the amorphous regions and can increase the modulus of CPBs. However, with an increase in MAPP content from $2 \mathrm{wt} \%$ to $4 \mathrm{wt} \%$, there was a decrease in the mechanical properties of the boards. This result may be attributed to the migration of excess MAPP around the fibers, causing their entanglement among themselves rather than with the PP films, which results in slippage (Mohanty et al. 2004). Therefore, excessive MAPP was not beneficial for improving the internal compatibility of the CPBs. Wang et al. (2012) and Zhu et al. (2014) also found that excessive MAPP resulted in weaker hindrance to the reorientation of the hydroxymethyl groups $\left(-\mathrm{CH}_{2} \mathrm{OH}\right)$ by conglomerating together, leading to weaker bonding between MAPP and PP, or among MAPP molecules themselves.

The A171 treatment significantly influenced the mechanical properties of the CPBs when the concentration of silane solution increased from $0 \mathrm{wt} \%$ to $3 \mathrm{wt} \%$. The MOR, MOE, and IB of the CPBs increased by $31.0 \%, 21.9 \%$, and $44.7 \%$, respectively. These results corresponded to A171 modification improving the interaction and adhesion between cotton stalk fibers and PP films. The functional group $-\mathrm{OCH}_{3}$ in $\mathrm{A} 171$ was hydrolyzed in the presence of water and acid, yielding active silanol groups, which have a high affinity for cotton stalk fibers. These silanol groups are adsorbed onto the fiber surface by the formation of hydrogen bonds (-Si---O---Si-), which then become converted into covalent bonds (-Si-O-C-) (Geng and Laborie 2010; Fang et al. 2014; Asim et al. 2016; Dayo et al. 2018). The mechanical properties of $2 \mathrm{wt} \%$ PMDI-treated CPBs were better than those of 2 wt $\%$ MAPP-treated CPBs and 3 wt\% A171-treated CPBs. 

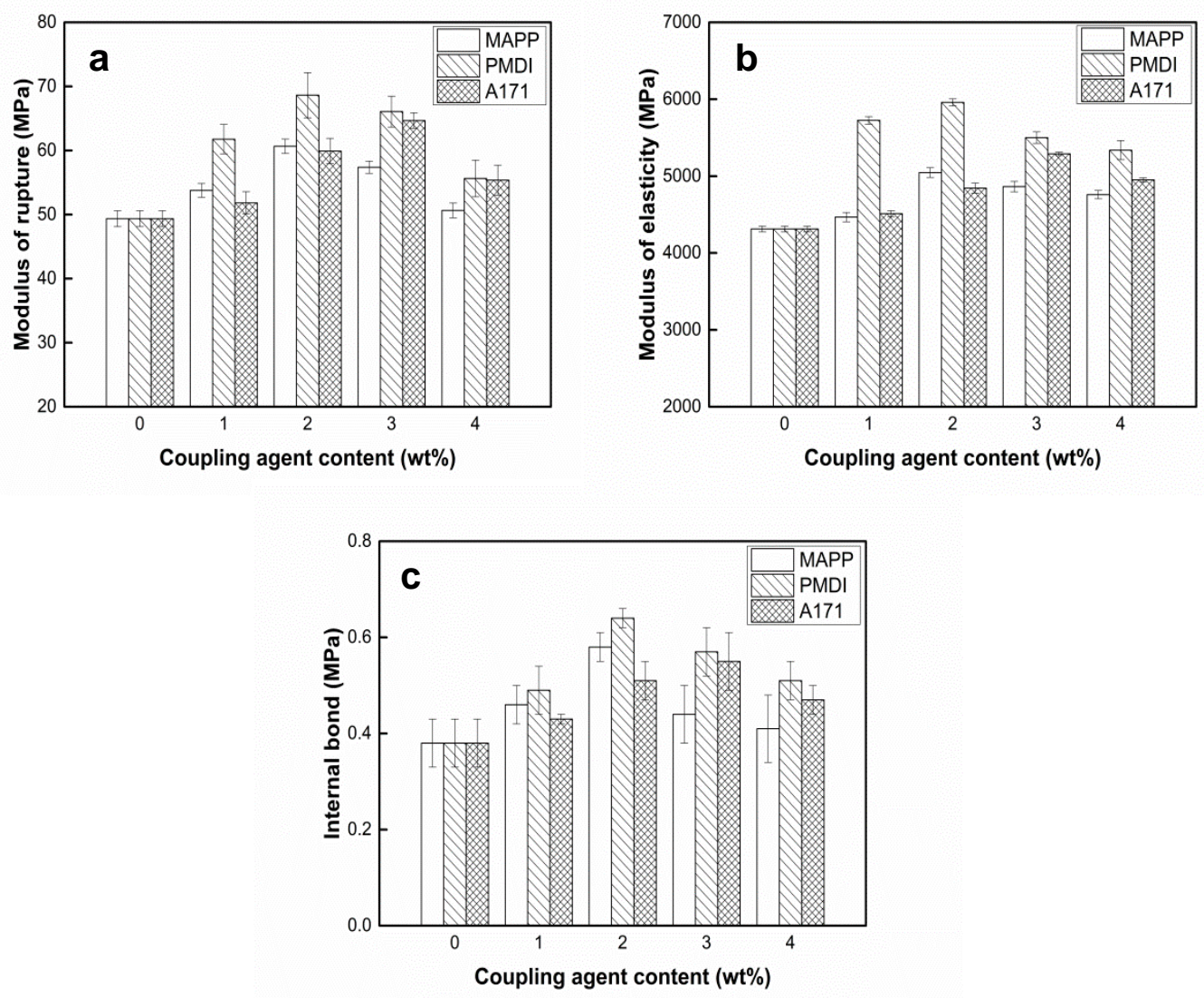

Fig. 3. Effects of coupling agents on the mechanical properties of CPBs

Furthermore, the mechanical properties of all the treated and non-treated CPBs were better than those of medium-density particleboards and fiberboards, while the thickness swelling needs improvement (Table 3). Compared to medium density particleboard, the MOR, MOE, and IB of $2 \mathrm{wt} \%$ PMDI-treated CPBs were increased by $316.0 \%, 116.7 \%$, and $16.4 \%$, respectively, while the thickness swelling was reduced by $32.1 \%$.

Table 3. Mechanical Properties and Thickness Swelling of Various Wood-based Composites

\begin{tabular}{|c|c|c|c|c|c|c|}
\hline Composite Name & $\begin{array}{l}\text { MOR } \\
(\mathrm{MPa})\end{array}$ & $\begin{array}{l}\mathrm{MOE} \\
(\mathrm{MPa})\end{array}$ & $\begin{array}{c}\text { IB } \\
(\mathrm{MPa})\end{array}$ & $\begin{array}{l}\text { Thickness } \\
\text { Swelling (\%) }\end{array}$ & $\begin{array}{l}\text { Density } \\
\left(\mathrm{g} / \mathrm{cm}^{3}\right)\end{array}$ & Sources \\
\hline Non-treated CPBs & 49.37 & 4313.6 & 0.38 & 23.88 & 0.7 & \\
\hline $\begin{array}{l}2 \text { wt } \% \text { MAPP- } \\
\text { treated CPBs }\end{array}$ & 60.67 & 5046.9 & 0.53 & 16.10 & 0.7 & \\
\hline $\begin{array}{l}2 \text { wt\% PMDI- } \\
\text { treated CPBs }\end{array}$ & 68.64 & 5959.9 & 0.64 & 10.18 & 0.7 & \\
\hline $\begin{array}{l}3 \text { wt } \% \text { A171- } \\
\text { treated CPBs }\end{array}$ & 64.68 & 5290.0 & 0.55 & 15.23 & 0.7 & \\
\hline $\begin{array}{l}\text { Medium-density } \\
\text { particleboard }\end{array}$ & $\begin{array}{l}11 \text { to } \\
16.5\end{array}$ & $\begin{array}{c}1725 \text { to } \\
2750\end{array}$ & $\begin{array}{l}0.40 \text { to } \\
0.55\end{array}$ & 8 to 15 & $\begin{array}{l}0.64 \text { to } \\
0.8\end{array}$ & $\begin{array}{c}\text { ANSI } \\
\text { A208.1 } \\
(1999)\end{array}$ \\
\hline $\begin{array}{l}\text { Medium-density } \\
\text { fiberboard }\end{array}$ & 14 to 31 & $\begin{array}{l}1400 \text { to } \\
3100\end{array}$ & $\begin{array}{l}0.30 \text { to } \\
1.05\end{array}$ & 10 & 0.5 to 1.0 & $\begin{array}{c}\text { ANSI } \\
\text { A208.2 } \\
(2002)\end{array}$ \\
\hline
\end{tabular}




\section{Thickness Swelling}

The main objective of the surface treatment was to decrease the hydrophilicity of the cotton stalk fibers and establish a strong interface between the treated cotton stalk fibers and the PP films. Figure 4 depicts the effects of various coupling agent treatments on the thickness swelling of CPBs. It is evident that the treated boards showed decreased values of thickness swelling compared with the untreated boards, and the extent of decrease varied with the nature of the coupling agent treatment.

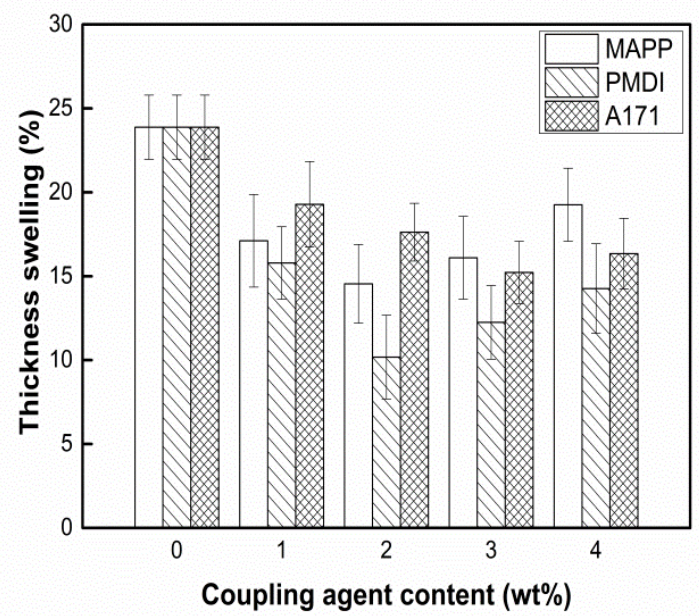

Fig. 4. Effects of coupling agents on thickness swelling of CPBs

The boards treated with 2 wt\% PMDI showed the least thickness swelling. This improved moisture resistance can be explained by an improved fiber-film adhesion, as strong chemical bonds were formed between the interfaces of the cotton stalk fibers and the PP films. Additionally, the reactive isocyanate of PMDI could most likely react with hydroxyl groups of cotton stalk fibers to form strong interfacial adhesion via chemical urethane bridges (Liang et al. 2013; Zhang et al. 2015).

MAPP builds up strong chemical bonds by forming an ester linkage with the hydroxyl groups of the fibers, which helps to decrease moisture intake caused by fiber debonding, thereby promoting efficient adhesive strength. This in turn reduces the extent of water absorption. The $2 \mathrm{wt} \%$ MAPP-treated CPBs showed a 39.5\% decrease in thickness swelling compared with the untreated boards. This result may be explained by the promoted dispersion of plastics into the cotton stalk fibers and the improved interfacial adhesion between fibers and films slowing down the water diffusion rate (Xie et al. 2010b). Furthermore, the decreased amount of hygroscopic hydroxyl groups in CPBs caused by esterification with anhydride groups contributed to the decreased thickness swelling (Zhou et al. 2013). However, CPBs with a MAPP content of $4 \mathrm{wt} \%$ exhibited greater thickness swelling than those modified with 2 wt $\%$ MAPP. This result may be caused by the increased amount of non-reacted maleic anhydride.

Silane modification decreased the thickness swelling of CPBs. The thickness swelling significantly decreased (from $23.88 \%$ to $15.23 \%$ ) when the cotton stalks were treated with 3 wt $\%$ silane solution, compared with non-treated boards. This result could be caused by the improved interfacial adhesion of cotton stalk fibers and PP films, causing more surface area of the hygroscopic fibers to be covered by the hydrophobic PP films. Additionally, the surface nature of the cotton stalk fibers was modified from a hydrophilic 
to a relatively hydrophobic level by the silane treatment, as A171 is a hydrophobic coating and can enhance water resistance ability. The results of the analysis of variance (ANOVA) (Table 4) revealed that all sources of variation were highly significant.

Table 4. ANOVA of Effect of Coupling Agent Content on Mechanical Properties and Thickness Swelling of CPBs

\begin{tabular}{|c|c|c|c|c|c|c|c|c|c|c|}
\hline \multirow{2}{*}{$\begin{array}{l}\text { Coupling } \\
\text { Agents }\end{array}$} & \multirow{2}{*}{$\begin{array}{l}\text { Variation } \\
\text { Sources }\end{array}$} & \multirow[t]{2}{*}{ DF } & \multicolumn{2}{|c|}{ MOR } & \multicolumn{2}{|c|}{ MOE } & \multicolumn{2}{|c|}{ IB } & \multicolumn{2}{|c|}{$\begin{array}{c}\text { Thickness } \\
\text { Swelling }\end{array}$} \\
\hline & & & MS & $\mathrm{F}$ & MS & $\mathrm{F}$ & MS & $\mathrm{F}$ & MS & $\mathrm{F}$ \\
\hline \multirow{2}{*}{ MAPP } & $\begin{array}{l}\text { Between } \\
\text { groups }\end{array}$ & 4 & 65.942 & $52.938^{\star \star}$ & $2.65 \times 10^{5}$ & $79.426^{\star *}$ & 0.018 & $6.533^{\star *}$ & 39.212 & $7.093^{\star \star}$ \\
\hline & $\begin{array}{l}\text { Within } \\
\text { groups }\end{array}$ & 10 & 1.246 & & 3341.04 & & 0.003 & & 5.528 & \\
\hline \multirow{2}{*}{ PMDI } & $\begin{array}{l}\text { Between } \\
\text { groups }\end{array}$ & 4 & 184.729 & $27.854^{\star \star}$ & $1.21 \times 10^{6}$ & $225.375^{\star *}$ & 0.028 & $14.795^{\star \star}$ & 82.823 & $15.608^{\star *}$ \\
\hline & $\begin{array}{l}\text { Within } \\
\text { groups }\end{array}$ & 10 & 6.632 & & 5352.168 & & 0.002 & & 5.307 & \\
\hline \multirow{2}{*}{ A171 } & $\begin{array}{l}\text { Between } \\
\text { groups }\end{array}$ & 4 & 114.12 & $36.702^{\star \star}$ & $4.37 \times 10^{5}$ & $263.499^{* *}$ & 0.013 & $7.621^{\star *}$ & 34.228 & $8.192^{\star *}$ \\
\hline & $\begin{array}{l}\text { Within } \\
\text { groups }\end{array}$ & 10 & 3.109 & & 1658.414 & & 0.002 & & 4.178 & \\
\hline
\end{tabular}

Compared with the untreated boards, the PMDI-treated boards showed the best properties, especially at the dosage of $2 \mathrm{wt} \%$. The boards treated with MAPP performed better than the A171-treated boards. These results may be due to the high viscosity of PMDI, making cotton stalk fibers stick together tightly. It is hypothesized that the hydrophilic cotton stalk fibers and hydrophobic PP films become more compatible due to the isocyanate groups of PMDI building covalent bonds with the hydroxyl groups of cotton stalk fibers, which can reduce the hydrophilicity of cotton stalk fibers (Xue et al. 2015). MAPP molecules have both polar groups and non-polar groups, which can change the interfacial compatibility between cotton stalk fibers and PP films. However, the reactions among the cotton stalk fibers, MAPP, and PP films were slow, since no catalysts were used in this study. The A171 improved the properties of CPBs through improved bonding at the fiber-film interface.

\section{Morphological Structure}

The interfacial properties of CPBs were investigated by SEM. Figure 5 shows the fractured surfaces of the various surface-treated and untreated CPBs. The SEM observations indicated that there was a considerable difference between the fiber-film interfaces of the treated and untreated boards (Mohanty and Nayak 2004; Jayamani et al. 2016).

Examining the untreated and A171-treated CPBs (Fig. 5a and 5d), many fiber pullouts and wide gaps between the fibers and PP were visible, which confirmed the poor interfacial adhesion and poor dispersion characteristics of the untreated fibers. However, the MAPP-treated fibers (Fig. 5b) exhibited better dispersion within the matrix in comparison to the untreated boards, which can be further correlated with the improved mechanical properties of these CPBs. After modification with 2 wt\% MAPP, the compatibility between the fibers and films was improved, and the interfacial boundary 
became indistinct. This result further confirmed that optimal MAPP content can improve the interfacial compatibility of CPBs.

Similarly, the micrographs of the PMDI-treated composites (Fig. 5c) showed efficient fiber-film adhesion, as observed from the decrease of fiber pullouts and gaps between the fibers and PP, as well as the good dispersion of the films into the fibers. The efficiency of PMDI modification from a morphological viewpoint can be further corroborated by mechanical findings.
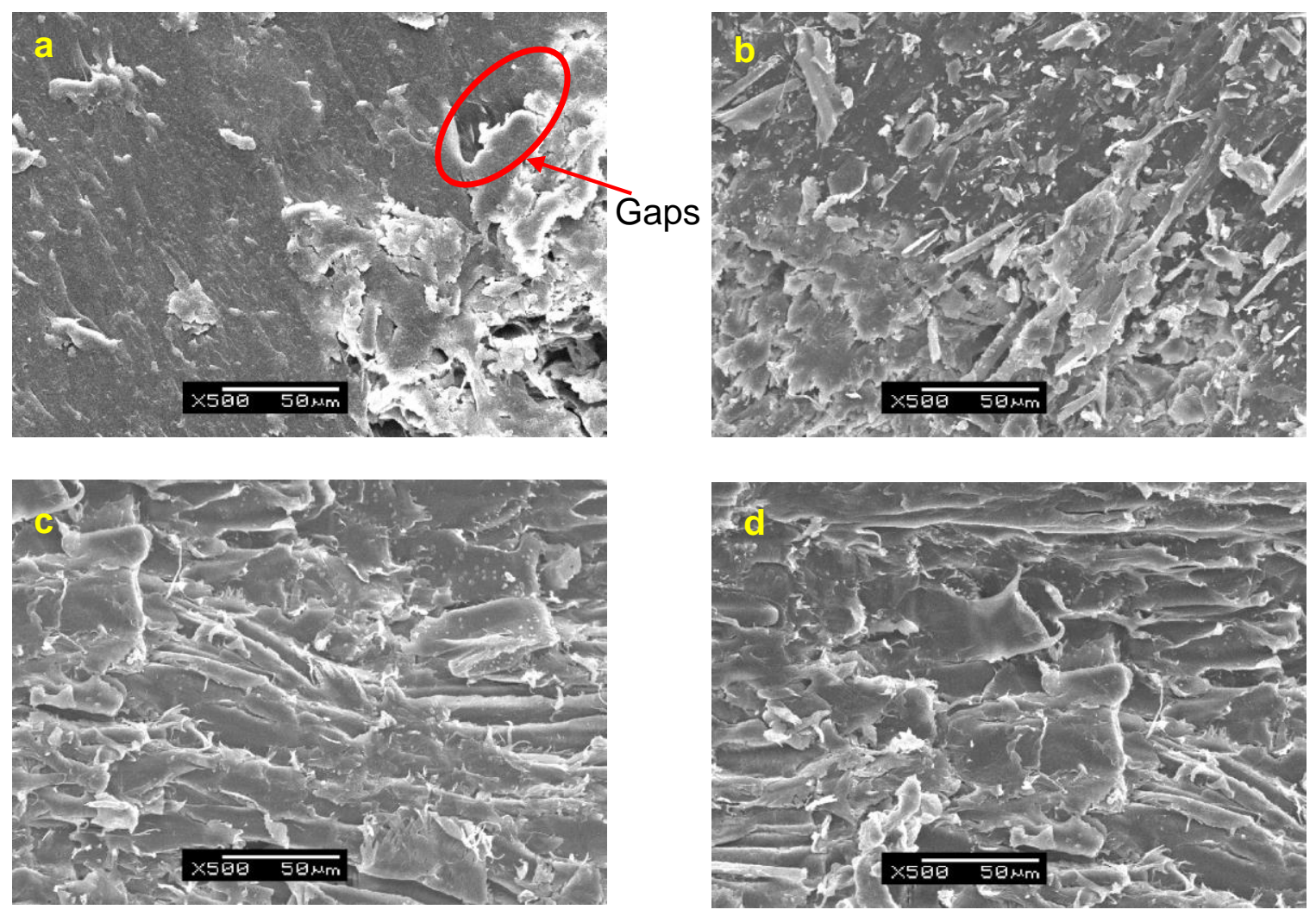

Fig. 5. Scanning electron micrographs of CPBs: (a) untreated, (b) 2 wt\% MAPP-treated, (c) 2 wt $\%$ PMDI-treated, and (d) 3 wt $\%$ A171-treated

\section{CONCLUSIONS}

1. Cotton stalk-polypropylene film boards were surface-treated with three different kinds of coupling agents and were fabricated by hot pressing. The mechanical and physical tests revealed that the modulus of rupture (MOR), modulus of elasticity (MOE), internal bond (IB) strength, and thickness swelling values of the boards were significantly improved by the modification of polymeric methyl diphenyl diisocyanate (PMDI), to a greater extent than with MAPP or A171. The boards treated with $2 \mathrm{wt} \%$ PMDI exhibited optimum properties, with a $39.0 \%$ increase in MOR, a 38.2\% increase in MOE, a $68.4 \%$ increase in IB, and a $57.4 \%$ decrease in thickness swelling compared with untreated boards.

2. The mechanical properties of the coupling agent-treated cotton stalk-polypropylene film boards (CPBs) were better than those of medium-density particleboards and 
fiberboards, but the thickness swelling needs further improvement. Compared to medium density particleboard, the MOR, MOE, and IB of $2 \mathrm{wt} \%$ PMDI-treated CPBs were increased by $316.0 \%, 116.7 \%$, and $16.4 \%$, respectively, while the thickness swelling was reduced by $32.1 \%$.

3. The morphology analysis of the interfacial region confirmed efficient interfacial adhesion in the coupling agent-treated boards, which was further corroborated by mechanical findings. Compared to untreated boards, the $2 \mathrm{wt} \%$ PMDI-treated boards showed efficient fiber-film adhesion.

4. Polypropylene films could effectively reinforce cotton stalks to fabricate oriented boards with the optimal type and content of coupling agent.

\section{ACKNOWLEDGMENTS}

The authors appreciate the financial support from the Education Department of Henan Province (Grant No. 18B550011) and Xinyang Agriculture and Forestry University (Grant No. 201601010).

\section{REFERENCES CITED}

Abdul Khalil, H. P. S., Tehrani, M. A., Davoudpour, Y., Bhat, A. H., Jawaid, M., and Hassan, A. (2013). "Natural fiber reinforced poly(vinyl chloride) composites: A review," J. Reinf. Plast. Comp. 32(5), 330-356. DOI: 10.1177/0731684412458553

ANSI A208.1 (1999). "Particleboard," American National Standards Institute, New York, NY, USA.

ANSI A208.2 (2002). "Medium density fiberboard (MDF) for interior applications," American National Standards Institute, New York, NY, USA.

Ashori, A., and Nourbakhsh, A. (2009). "Polypropylene cellulose-based composites: The effect of bagasse reinforcement and polybutadiene isocyanate treatment on the mechanical properties," J. Appl. Polym. Sci. 111(4), 1684-1689. DOI: 10.1002/app.29189

Asim, M., Jawaid, M., Abdan, K., and Ishak, M. R. (2016). "Effect of alkali and silane treatments on mechanical and fibre-matrix bond strength of kenaf and pineapple leaf fibres," J. Bionic Eng. 13(3), 426-435. DOI: 10.1016/s1672-6529(16)60315-3

Askanian, H., Verney, V., Commereuc, S., Guyonnet, R., and Massardier, V. (2015). "Wood polypropylene composites prepared by thermally modified fibers at two extrusion speeds: Mechanical and viscoelastic properties," Holzforschung 69(3), 313319. DOI: $10.1515 /$ hf-2014-0031

Aydemir, D., Kiziltas, A., Kiziltas, E. E., Gardner, D. J., and Gunduz, G. (2015). "Heat treated wood-nylon 6 composites," Compos. Part B-Eng. 68, 414-423. DOI: 10.1016/j.compositesb.2014.08.040

Ben Mbarek, T., Robert, L., Sammouda, H., Charrier, B., Orteu, J.-J., and Hugot, F. (2013). "Effect of acetylation and additive on the tensile properties of wood fiberhigh-density polyethylene composite," J. Reinf. Plast. Comp. 32(21), 1646-1655. DOI: $10.1177 / 0731684413505256$

Daghigh, V., Lacy, Jr., T. E., Pittman, Jr., C. U., and Daghigh, H. (2018). “Influence of 
maleated polypropylene coupling agent on mechanical and thermal behavior of latania fiber-reinforced PP/EPDM composites," Polym. Composite. 39(53), E1751E1759. DOI: $10.1002 / \mathrm{pc} .24752$

Dayo, A. Q., Zegaoui, A., Nizamani, A. A., Kiran, S., Wang, J., Derradji, M., Cai, W.-a., and Liu, W.-b. (2018). "The influence of different chemical treatments on the hemp fiber/polybenzoxazine based green composites: Mechanical, thermal and water absorption properties," Mater. Chem. Phys. 217, 270-277. DOI: 10.1016/j.matchemphys.2018.06.040

Fang, L., Chang, L., Guo, W.-j., Chen, Y., and Wang, Z. (2014). "Influence of silane surface modification of veneer on interfacial adhesion of wood-plastic plywood," Appl. Surf. Sci. 288, 682-689. DOI: 10.1016/j.apsusc.2013.10.098

GB/T 17657 (2013). "Test methods of evaluating the properties of wood-based panels and surface decorated wood-based panels," Standardization Administration of the People's Republic of China, Beijing, China.

Geng, Y., and Laborie, M.-P. G. (2010). "The impact of silane chemistry conditions on the properties of wood plastic composites with low density polyethylene and high wood content," Polym. Composite. 31(5), 897-905. DOI: 10.1002/pc.20873

Homkhiew, C., Ratanawilai, T., and Thongruang, W. (2015). "Composites from recycled polypropylene and rubberwood flour: Effects of composition on mechanical properties," J. Thermoplast. Compos. 28(2), 179-194. DOI:

10.1177/0892705712475019

Huang, C.-W., Yang, T.-C., Hung, K.-C., Xu, J.-W., and Wu, J.-H. (2018). "The effect of maleated polypropylene on the non-isothermal crystallization kinetics of wood fiberreinforced polypropylene composites," Polymers-Basel 10(4). DOI: 10.3390/polym 10040382

Jariwala, H., and Jain, P. (2019). "A review on mechanical behavior of natural fiber reinforced polymer composites and its applications," J. Reinf. Plast. Comp. 38(10), 441-453. DOI: 10.1177/0731684419828524

Jayamani, E., Hamdan, S., Bin Bakri, M. K., Heng, S. K., Rahman, M. R., and Kakar, A. (2016). "Analysis of natural fiber polymer composites: Effects of alkaline treatment on sound absorption," J. Reinf. Plast. Comp. 35(9), 703-711. DOI: $10.1177 / 0731684415620046$

Jin, X., Zhang, X., Xu, C., and Nie, S. (2019). "Effect of bamboo fibers with different coupling agents on the properties of poly(hydroxybutyrate-co-valerate) biocomposites," J. Appl. Polym. Sci. 136(20). DOI: 10.1002/app.47533

Kalia, S., Kaith, B. S., and Kaur, I. (2009). "Pretreatments of natural fibers and their application as reinforcing material in polymer composites-A review," Polym. Eng. Sci. 49(7), 1253-1272. DOI: 10.1002/pen.21328

Karmarkar, A., Chauhan, S. S., Modak, J. M., and Chanda, M. (2007). "Mechanical properties of wood-fiber reinforced polypropylene composites: Effect of a novel compatibilizer with isocyanate functional group," Compos. Part A-Appl. S. 38(2), 227-233. DOI: 10.1016/j.compositesa.2006.05.005

Kumar, V., Tyagi, L., and Sinha, S. (2011). "Wood flour-reinforced plastic composites: A review," Rev. Chem. Eng. 27(5-6), 253-264. DOI: 10.1515/revce.2011.006

Liang, K., Gao, Q., and Shi, S.Q. (2013). "Kenaf fiber/soy protein based biocomposites modified with poly(carboxylic acid) resin," J. Appl. Polym. Sci. 128(2), 1213-1218. DOI: 10.1002/app.38330

Ma, L., He, L. J., and Shao, S. Y. (2017). "Study on effect of surface treating method on 
mechanical behavior of three plant fiber reinforced polypropylene composites," Polym. Polym. Compos. 25(1), 93-102. DOI: 10.1177/096739111702500113

Mohanty, S., Nayak, S. K., Verma, S. K., and Tripathy, S. S. (2004). "Effect of MAPP as coupling agent on the performance of sisal-PP composites," J. Reinf. Plast. Comp. 23(18), 2047-2063. DOI: 10.1177/0731684404041711

Naghmouchi, I., Espinach, F. X., Mutjé, P., and Boufi, S. (2015). "Polypropylene composites based on lignocellulosic fillers: How the filler morphology affects the composite properties," Mater. Design 65, 454-461. DOI:

10.1016/j.matdes.2014.09.047

Ou, R., Wang, Q., Wolcott, M. P., Sui, S., Xie, Y., and Song, Y. (2014). "Effects of chemical modification of wood flour on the rheological properties of high-density polyethylene blends," J. Appl. Polym. Sci. 131(23). DOI: 10.1002/app.41200

Pisanu, L., Barbosa, J., Souza, R., and Nascimento, M. (2019). "Evaluating the influence of coupling agents in the structural properties of polypropylene coconut fiber composites," Mater. Res. Express. 6(11). DOI: 10.1088/2053-1591/ab4626

Poletto, M., and Zattera, A. J. (2017). "Mechanical and dynamic mechanical properties of polystyrene composites reinforced with cellulose fibers: Coupling agent effect," $J$. Thermoplast. Compos. 30(9), 1242-1254. DOI: 10.1177/0892705715619967

Qi, C., Guo, K., and Liu, Y. (2012). "Preparation and properties of cotton stalk bundles and high-density polyethylene composites using hot-press molding," J. Reinf. Plast. Comp. 31(15), 1017-1024. DOI: 10.1177/0731684411435726

Sobczak, L., Brüggemann, O., and Putz, R. F. (2013). "Polyolefin composites with natural fibers and wood-modification of the fiber/filler-matrix interaction," J. Appl. Polym. Sci. 127(1), 1-17. DOI: 10.1002/app.36935

Tanasă, F., Zănoagă, M., Teacă, C.-A., Nechifor, M., and Shahzad, A. (2020). “Modified hemp fibers intended for fiber-reinforced polymer composites used in structural applications-A review. I. Methods of modification," Polym. Composite. 41(1), 5-31. DOI: $10.1002 /$ pc. 25354

Verma, D., and Jain, S. (2017). "Effect of natural fibers surface treatment and their reinforcement in thermo- plastic polymer composites: A review," Curr. Org. Synth. 14(2), 186-199. DOI: 10.2174/1570179413666160921114114

Wang, H., Memon, H., Hassan, E. A. M., Miah, M. S., and Ali, M. A. (2019). "Effect of jute fiber modification on mechanical properties of jute fiber composite," Materials 12(8). DOI: $10.3390 / \mathrm{ma1} 2081226$

Wang, Y., Cao, J., Zhu, L., and Zhao, G. (2012). "Interfacial compatibility of wood flour/polypropylene composites by stress relaxation method," J. Appl. Polym. Sci. 126(51), E89-E95. DOI: 10.1002/app.36682

Xie, Y., Hill, C. A. S., Xiao, Z., Militz, H., and Mai, C. (2010a). "Silane coupling agents used for natural fiber/polymer composites: A review," Compos. Part A-Appl. S. 41(7), 806-819. DOI: 10.1016/j.compositesa.2010.03.005

Xie, Y., Xiao, Z., Grüneberg, T., Militz, H., Hill, C. A. S., Steuernagel, L., and Mai, C. (2010b). "Effects of chemical modification of wood particles with glutaraldehyde and 1,3-dimethylol-4,5-dihydroxyethyleneurea on properties of the resulting polypropylene composites," Compos. Sci. Technol. 70(13), 2003-2011. DOI: 10.1016/j.compscitech.2010.07.024

Xue, D., Lei, W., Deng, Y., Jing, L., and Liu, Q. (2015). "Effect of interface modification on mechanical and thermal properties of high-density polyethylene/silvergrass composites," J. Thermoplast. Compos. 28(1), 128-141. DOI: 
10.1177/0892705714526911

Xue, D., Yu, W. W., Liu, Q., Jing, L., Liu, X. J., and Lei, W. (2013). "Effects of PMDI treatments on thermal properties of silvergrass reinforced high density polyethylene composites," Appl. Mech. Mater. 423-426, 84-88. DOI:

10.4028/www.scientific.net/AMM.423-426.84

Yan, Z., Zhang, J., Zhang, H., and Wang, H. (2013). "Improvement of mechanical properties of noil hemp fiber reinforced polypropylene composites by resin modification and fiber treatment," Adv. Mater. Sci. Eng. 2013, 941617. DOI: $10.1155 / 2013 / 941617$

Yu, W. W., Li, J., and Cao, Y. P. (2013). "Effects of PMDI modified on physicomechanical properties of silvergrass reinforced high density polyethylene composites," Adv. Mat. Res. 750-752, 38-42. DOI: 10.4028/www.scientific.net/AMR.750-752.38

Zhang, H. (2014). "Effect of a novel coupling agent, alkyl ketene dimer, on the mechanical properties of wood-plastic composites," Mater. Design 59, 130-134. DOI: $10.1016 /$ j.matdes.2014.02.048

Zhang, Y.-H., Zhu, W.-Q., Gao, Z.-H., and Gu, J.-Y. (2015). "Effects of crosslinking on the mechanical properties and biodegradability of soybean protein-based composites," J. Appl. Polym. Sci. 132(5). DOI: 10.1002/app.41387

Zhao, Y., Qiu, J., Feng, H., and Zhang, M. (2012). "The interfacial modification of rice straw fiber reinforced poly(butylene succinate) composites: Effect of aminosilane with different alkoxy groups," J. Appl. Polym. Sci. 125(4), 3211-3220. DOI: 10.1002/app.36502

Zhou, X., Yu, Y., Lin, Q., and Chen, L. (2013). "Effects of maleic anhydride-grafted polypropylene (MAPP) on the physico-mechanical properties and rheological behavior of bamboo powder-polypropylene foamed composites," BioResources 8(4), 6263-6279. DOI: 10.15376/biores.8.4.6263-6279

Zhu, L., Cao, J., Wang, Y., Liu, R., and Zhao, G. (2014). "Effect of MAPP on interfacial compatibility of wood flour/polypropylene composite evaluated with dielectric approach," Polym. Composite. 35(3), 489-494. DOI: 10.1002/pc.22686

Article submitted: June 25, 2015; Peer review completed: October 18, 2015; Revised version received and accepted: September 17, 2020; Published: September 25, 2020. DOI: 10.15376/biores.15.4.8617-8630 